\title{
MicroRNA-based molecular classification of non-BRCA1/2 hereditary breast tumours
}

\author{
M Tanic ${ }^{1,7}$, E Andrés ${ }^{2}$, S M Rodriguez-Pinilla ${ }^{3}$, I Marquez-Rodas ${ }^{4}$, M Cebollero-Presmanes ${ }^{5}$, V Fernandez ${ }^{1}$, \\ A Osorio ${ }^{1}$, J Benítez ${ }^{1}$ and B Martinez-Delgado*,1,6 \\ ${ }^{1}$ Human Genetics Group, Spanish National Cancer Research Centre (CNIO) y Centro de Investigación Biomédica en Red \\ de Enfermedades Raras (CIBERER), Madrid, Spain; ${ }^{2}$ Bioinfo Unit, Spanish National Cancer Research Centre (CNIO), Madrid, Spain; \\ ${ }^{3}$ Pathology Department, Fundación Jimenez Díaz, Madrid, Spain; ${ }^{4}$ Servicio de Oncología Médica, Instituto de Investigación \\ Sanitaria Gregorio Marañón, Universidad Complutense, Madrid, Spain; ${ }^{5}$ Servicio de anatomía patológica, Instituto \\ de Investigación Sanitaria Gregorio Marañón, Universidad Complutense, Madrid, Spain and ' Molecular Genetics Unit, Human \\ Genetics Section, Instituto de Investigación en Enfermedades Raras IIER, Instituto de Salud Carlos III (ISCIII), Madrid, Spain
}

Background: Hereditary breast cancer comprises $5-10 \%$ of all breast cancers. Mutations in two high-risk susceptibility genes, BRCA1 and BRCA2, along with rare intermediate-risk genes and common low-penetrance alleles identified, altogether explain no more than $45 \%$ of the high-risk breast cancer families, although the majority of cases are unaccounted for and are designated as BRCAX tumours. Micro RNAs have called great attention for classification of different cancer types and have been implicated in a range of important biological processes and are deregulated in cancer pathogenesis.

Methods: Here we have performed an exploratory hypothesis-generating study of miRNA expression profiles in a large series of 66 primary hereditary breast tumours by microarray analysis.

Results: Unsupervised clustering analysis of miRNA molecular profiles revealed distinct subgroups of BRCAX tumours, 'normallike' BRCAX-A, 'proliferative' BRCAX-B, 'BRCA1/2-like' BRCAX-C and 'undefined' BRCAX-D subgroup. These findings introduce a new insight in the biology of hereditary breast cancer, defining specific BRCAX subgroups, which could help in the search for novel susceptibility pathways in hereditary breast cancer.

Conclusion: Our data demonstrate that BRCAX hereditary breast tumours can be sub-classified into four previously unknown homogenous groups characterised by specific miRNA expression signatures and histopathological features.

Breast cancer continues to be the most common cancer among women and second leading cause of cancer deaths. Only about $5-10 \%$ of all breast cancer cases arise in families with various affected members throughout several generations that follow a pattern of autosomal dominant inheritance, with earlier age of onset, and/or presenting bilateral/multiple tumours and are considered to be hereditary breast cancer cases.

Germline mutations in two high-susceptibility genes, BRCA1 and BRCA2, can account for only $\sim 20-25 \%$ of hereditary breast cancer cases (Bradbury and Olopade, 2007), and along with other rare intermediate-risk genes identified through re-sequencing studies of candidate genes involved in DNA damage repair pathway and common low-susceptibility alleles explain less than a half of hereditary breast cancer cases. More than $50 \%$ of breast cancer cases arising in high-risk families that fulfil the criteria for a hereditary cancer syndrome are unaccounted for, and are designated as non-BRCA1/2 or BRCAX tumours (Rahman and Stratton, 1998; Palacios et al, 2008; Stratton and Rahman, 2008;

\footnotetext{
*Correspondence: Dr B Martinez-Delgado; E-mail: bmartinezd@isciii.es

${ }^{7}$ Present address: Laboratory for Molecular Genetics, Experimental Oncology Department, Institute for Oncology and Radiology of Serbia (IORS), Belgrade, Serbia.
}

Received 20 April 2013; revised 11 September 2013; accepted 13 September 2013; published online 8 October 2013 
Mavaddat et al, 2010). These tumours represent not only a big 'black box' in terms of our understanding of the underlying biology of these tumours but also represent a major problem for genetic counselling and management of these patients and their families.

Due to difficulties in acquisition of fresh frozen tissue material, there have been only a handful of studies aimed at characterising molecular signature of these tumours by gene expression profiling (Hedenfalk et al, 2003). Have demonstrated in a small series of 19 hereditary tumours that BRCAX tumours have heterogeneous mRNA expression profiles and could be sub-classified in at least two subgroups with different gene expression signature. Previous results from our group (Fernandez-Ramires et al, 2010) supported this notion identifying two subgroups of BRCAX tumours, one of these groups showing a 'BRCA1-like' gene expression profile.

Discovery of miRNAs, short non-coding single-stranded RNA molecules that negatively regulate gene expression by inducing either translational repression or mRNA degradation depending on the level of complementarity to its target mRNA at the $3^{\prime} \mathrm{UTR}$, has improved our understanding of gene regulation. It has been demonstrated that miRNAs have a significant role in various biological processes, including differentiation and development, metabolism, regulation of cell proliferation and apoptosis (Inui et al, 2010). Deregulation of miRNA expression has been extensively implicated in cancer pathogenesis in various tumour types (Croce, 2009; Lujambio and Lowe, 2012). Further, miRNA expression is tissue specific and it has been demonstrated that miRNA expression profiling is more robust in classification of tumours of different origin (Lu et al, 2005). Specifically, in breast cancer, a number of studies defined miRNA expression profiles associated with sporadic breast tumours (Iorio et al, 2005; Volinia et al, 2006, 2012), specific breast cancer subtypes (Blenkiron et al, 2007; Fassan et al, 2009) and tumour biological features such as hormone receptor and HER2 status, metastasis, progression or proliferation (Mattie et al, 2006; Tavazoie et al, 2008; Lowery et al, 2009).

There has been longstanding expectation that evolution in molecular profiling may result in pathological classification that more directly reflects the genetic aetiology of non-BRCA1/2 tumours. Unfortunately, gene expression profiling studies have not lived to these expectations primarily due to technical and logistic difficulties related to acquisition of fresh tumour material. Given that miRNAs are very stable molecules, shown to be well preserved in paraffin-embedded tissues and also present in body fluids, they represent an ideal class of cancer biomarkers and have proven to be useful for cancer classification.

Here we studied global miRNA expression in a large series of 66 FFPE hereditary breast tumours using miRNA microarrays with the aim to explore BRCAX tumour heterogeneity based on their miRNA signatures. We have shown that BRCAX tumours can be sub-classified into four homogenous groups (BRCAX-A, -B, -C, and -D) characterised by specific miRNA expression signatures and histopathological features. These findings introduce a new insight in biology of hereditary breast cancer, defining specific BRCAX subgroups that could help in the search for novel susceptibility pathways in hereditary breast cancer.

\section{MATERIALS AND METHODS}

Sample set and imunochistochemical data. The breast tissue series used for microarray profiling consisted of 66 FFPE familial breast tumour samples, including 13 from BRCA1 mutation carriers, 10 from BRCA2 mutation carriers and 43 BRCAX tumours, 10 sporadic breast carcinomas, and 4 normal breast tissue samples. Formalin-fixed paraffin-embedded (FFPE) breast tumour samples used in this study were acquired through several participating Spanish hospitals (Gregorio Marañon, Hospital San Pablo, Fundacion Jimenez Diaz, Hospital La Paz, H Santa Caterina (Girona), P de Hierro, H Severo Ochoa, H Ramón y Cajal). Informed consent was obtained for all patients included in this study and the research project has the approval of the institutional ethics committee of Instituto de Salud Carlos III. All patients belong to high-risk breast cancer families and were selected according to Spanish Medical Oncology Society (http://www. seom.org/, SEOM) inclusion criteria. All patients have undergone full BRCA1/2 gene testing for mutations and large rearrangements using standard procedures (Osorio et al, 2000; Poggio et al, 2000; Bradbury and Olopade, 2007). Individuals without mutations identified in BRCA1 or BRCA2 genes were designated as BRCAX. Normal breast tissues were obtained after breast reduction surgery from healthy individuals with no family history of breast cancer.

RNA extraction. For each sample, tumoural area was marked by the pathologist, FFPE blocks were cut in $5 \times 30 \mu \mathrm{m}$ sections and tumour tissue was isolated by needle macrodissection for subsequent RNA extraction. Total RNA was extracted using miRNeasy FFPE kit (Qiagen, Valencia, CA, USA) according to the manufacturer's instructions, whereas tissue digestion step was performed using $20 \mathrm{mg} \mu \mathrm{l}^{-1}$ Proteinase K (Roche, Basel, Switzerland) for overnight incubation step at $55{ }^{\circ} \mathrm{C}$. RNA quantity was assessed by NanoDrop Spectrophotometer (Nanodrop Technologies, Wilmington, DE, USA).

Microarray hybridisation and data preprocessing. Microarray expression profiling was performed using miRCURY LNA microRNA Array v.11 (Exiqon A/S, Vedbaek, Denmark), in a one-colour experimental design. Labelling and hybridisation procedure was performed as recommended by manufacturer, using miRCURY LNA microRNA Power Labeling Kit (Exiqon). Briefly, $300 \mathrm{ng}$ of total RNA was labelled with $\mathrm{Hy} 3$ fluorescent dye and subsequently hybridised over $16 \mathrm{~h}$ at $56^{\circ} \mathrm{C}$ onto a miRNA microarray chip (v.11.0—hsa, mmu \& rno) containing 1940 capture probes in four replicates, including 830 human miRNAs annotated in miRBasev.11 database and 434 hsa- miRPlus probes. A set of 10 synthetic spike-in RNAs was added to total RNA sample before labelling and later used for quality control. Processed slides were scanned with Agilent Array scanner (Agilent Technologies, Santa Clara, CA, USA), with the laser set to $635 \mathrm{~nm}$, at Power 80 and PMT 70 setting, and a scan resolution of $10 \mu \mathrm{m}$. Fluorescence intensities on scanned images were quantified using Feature Extraction software (Agilent Technologies, Santa Clara, CA, USA) using the modified Exiqon protocol. Average processed intensity values of the replicate spots were background subtracted using Normexp, $\log _{2}$-transformed, and subjected to further analysis. Microarray dataset is publicly available at the GEO database http://www.ncbi.nlm.nih.gov/geo/info/linking.html under the GEO accession number GSE44899.

Raw data were quantile-normalised for inter-array variability using $\mathrm{R} /$ Bioconductor. Data were pre-processed to eliminate miRNAs with uniformly low expression $\left(\log _{2}\right.$ intensity $<6.5$ ) or with low expression variation (variance $<0.1$ ) across the experiments, retaining 444 miRNAs (276 hsa-miR +168 hsa-miRPlus).

Class discovery methods. Normalised data were median-centred and unsupervised average linkage hierarchical clustering analysis using Pearson correlation with uncentered metrics was performed using Gene Cluster (Eisen et $a l, 1998$ ) and visualised by Treeview (http://rana.stanford.edu/software; Stanford University, USA). Consensus Clustering module available in the Gene Pattern suite (Reich et al, 2006) was used for class discovery and clustering validation. This method facilitates the discovery of biologically meaningful clusters by assessing the stability of the discovered clusters by means of resampling techniques. The consensus clustering analyses were run with a KNN means algorithm with 
2, 3, 4, and 5 centroids using 500 resampling iterations. The consensus among the multiple runs is assessed and summarised in a consensus matrix and $\Delta \mathrm{G}$ plot. This matrix is used as a visualisation tool to estimate the composition and number of the clusters, whereas the $\Delta \mathrm{G}$ plot indicates the change in free energy with every additional group added.

Differential expression analysis. Differential expression analysis was performed using linear models (limma) $t$-test, implemented in the POMELO II tool from Asterias package (http://asterias.bioinfo.cnio.es) (Bignell et al, 2000). The estimated significance (unadjusted $P$-values) were corrected for multiple hypotheses testing using Benjamini and Hochberg false discovery rate (FDR) adjustment and $Q$-values ( adjusted $P$-values) were reported (Benjamini et al, 2001). Those miRNAs with $Q$-value $<0.05$ were selected as significantly differentially expressed.

Expression profile similarity between tumour types. We used the Pearson's Correlation coefficient as the metric of similarity for two profiles of different tumour types (BRCAX-A, BRCAX-B, BRCAX-C, BRCAX-D, BRCA1/2, SPORADIC and NORMAL). Expression values for each miRNA in a given tumour type were averaged and aggregated Pearson's correlation coefficient was calculated using statistical software Stata.12.1 (StataCorp LP, TX, USA) and associated two-tailed $P$-values were calculated by onesample $t$-test with the degree of freedom of $n-2$, where $n$ is the total number of genes, as described in (Liao and Zhang, 2006). Correlation matrix graph was built using corrgram package in $\mathrm{R}$ version 2.15.2 (http://www.r-project.org). Linear regression analysis using least squares method was used to fit linear curve to miRNA expression scatter plot.

Functional annotation and gene set enrichment analysis. The list of confirmed miRNA target genes was compiled from: Tarbase v.5c (DIANA lab, http://diana.cslab.ece.ntua.gr/tarbase/), miRecords (http://mirecords.biolead.org/) and miTarBase (http:// mirtarbase.mbc.nctu.edu.tw/index.html). Functional annotation analysis of Gene Ontology (GO) terms associated with a given gene list of mRNA targets within each miRNA cluster was performed using DAVID 6.7 bioinformatic tool (Huang da et al, 2009). GO functional categories with $P$-values under 0.05 after correction for multiple hypotheses testing by Benjamini and Hochberg were considered as statistically significant.

Immunohistochemistry and statistical analysis. Imunochistochemical information on tumour grade, oestrogen receptor (ER), progesterone receptor (PR), human epidermal growth factor receptor 2 (HER2/ErbB2) gene expression and/or amplification, BRCA1 methylation, Ki-67, p53 and EGFR was available for 41 samples from tissue microarray described previously in (Palacios et al, 2003; Honrado et al, 2005, 2006). For remainder of samples (15) information on tumour grade, ER, PR, HER2/ErbB2 status was obtained from either hospital pathology report when available or by staining individual tumour sections using same criteria as described in (Honrado et al, 2006). Full information on imunochistochemical data is represented in Supplementary Table 1.

The $\chi^{2}$-test and Fisher's exact test were employed for the analysis of the homogeneity of the distribution of the expression of imunochistochemical markers, tumour grade and subtypes between the groups of tumours using SPSS 13.0 (SPSS, Chicago, IL, USA) and R/Bioconductor. Fisher's exact test permits calculation of precise probabilities in situation where sample sizes are small so the normal approximation and $\chi^{2}$ calculations are liable to be inaccurate. Two-tailed Fisher's exact test was used for pair-wise comparison of markers to detect differences between two groups of tumours.

\section{RESULTS}

We performed global miRNA expression analysis of more than 800 human miRNA genes in a large series of 66 hereditary breast carcinomas. The series included primary tumours from 13 BRCA1 mutation carriers, 10 BRCA2 and 43 non-BRCA12 tumours denominated hereafter as BRCAX tumours. In addition, we have analysed 10 sporadic breast carcinomas and 6 normal breast tissues obtained after breast reduction surgery from healthy donors. To avoid contamination with normal breast tissue, tumoural area on FFPE blocks was marked by a pathologist and macrodissected for subsequent total RNA extraction. Histopathological characteristics (ER, PR, HER2, EGFR, CK5, Ki-67), tumour subtype and age at diagnosis of BRCA1, BRCA2 and BRCAX tumours in this series (Supplementary Table S1) are fully representative to what has been reported in the literature.

Unsupervised hierarchical clustering of hereditary breast tumours. Unsupervised hierarchical clustering of 66 hereditary breast tumours (Figure 1) was performed over 444 miRNAs that were retained after filtering-out miRNAs with low expression variation (Variance $<0.1$ ) and low expression level $\left(\log _{2}\right.$ intensities <6.5). Clustering analysis revealed heterogeneous miRNA profiles among hereditary breast tumours that were separated in two main branches. It is been well documented that breast tumours can be classified into four stable molecular subtypes by mRNA profiling, with the most prominent discriminators being ER, HER2 and tumour differentiation. However, we observed that the clustering based on miRNA expression was not mainly driven by ER status. Clustering of HER2 positive tumours was evident, whereas triple negative (ER-, PR- and HER-) tumours were dispersed across the cluster. This indicates that the clustering of hereditary breast tumours by miRNAs is not fully driven by molecular subtypes and may carry additional information on these tumours, in line with reports on miRNA profiling in sporadic breast carcinomas (Rothe et al, 2011).

Interestingly, BRCA1 and BRCA2 tumours clustered together in the same sub-branch as a quite homogenous group with similar miRNA expression profiles, clearly separated from the BRCAX tumours. BRCAX tumours were separated into two branches with heterogeneous miRNA expression profile that demarcates several subgroups. One group of BRCAX samples were clustered along BRCA1- and BRCA2-mutated tumours, whereas samples in other branches had markedly different miRNA expression profiles.

Class discovery algorithms reveal four subgroups of BRCAX tumours. Unsupervised hierarchical clustering of the 43 BRCAX tumour samples showed several apparent subgroups (Figure 2A). Consensus clustering (GenePattern 2.0, Broad Institute, MA, USA) was used for class discovery for obtaining the most robust classification of BRCAX tumours. This analysis revealed the existence of four different subgroups among BRCAX tumours, namely BRCAX-A, -B, -C and -D (Figure $2 \mathrm{~B}$ and $\mathrm{C}$ ).

Interestingly, the BRCAX-C subgroup groups in the same branch with BRCA1/2-mutated tumours, whereas BRCAX-A group clusters along normal breast tissue (Supplementary Figure S1). Group B appears as a homogenous group of tumours, whereas group D lacked a specific miRNA signature and tumours in this group were dispersed across the cluster.

miRNA signatures defining BRCAX subgroups. To further characterise BRCAX subgroups, we have selected co-expressed miRNAs with correlation coefficient higher than $R^{2}>0.77$ that best discriminate between the groups. Three main miRNA clusters were identified, namely, Cluster 1 consisted of 62 miRNAs $\left(R^{2}>0.82\right)$, Cluster 2 consisted of 48 miRNAs $\left(R^{2}>0.77\right)$ and Cluster 3 with 

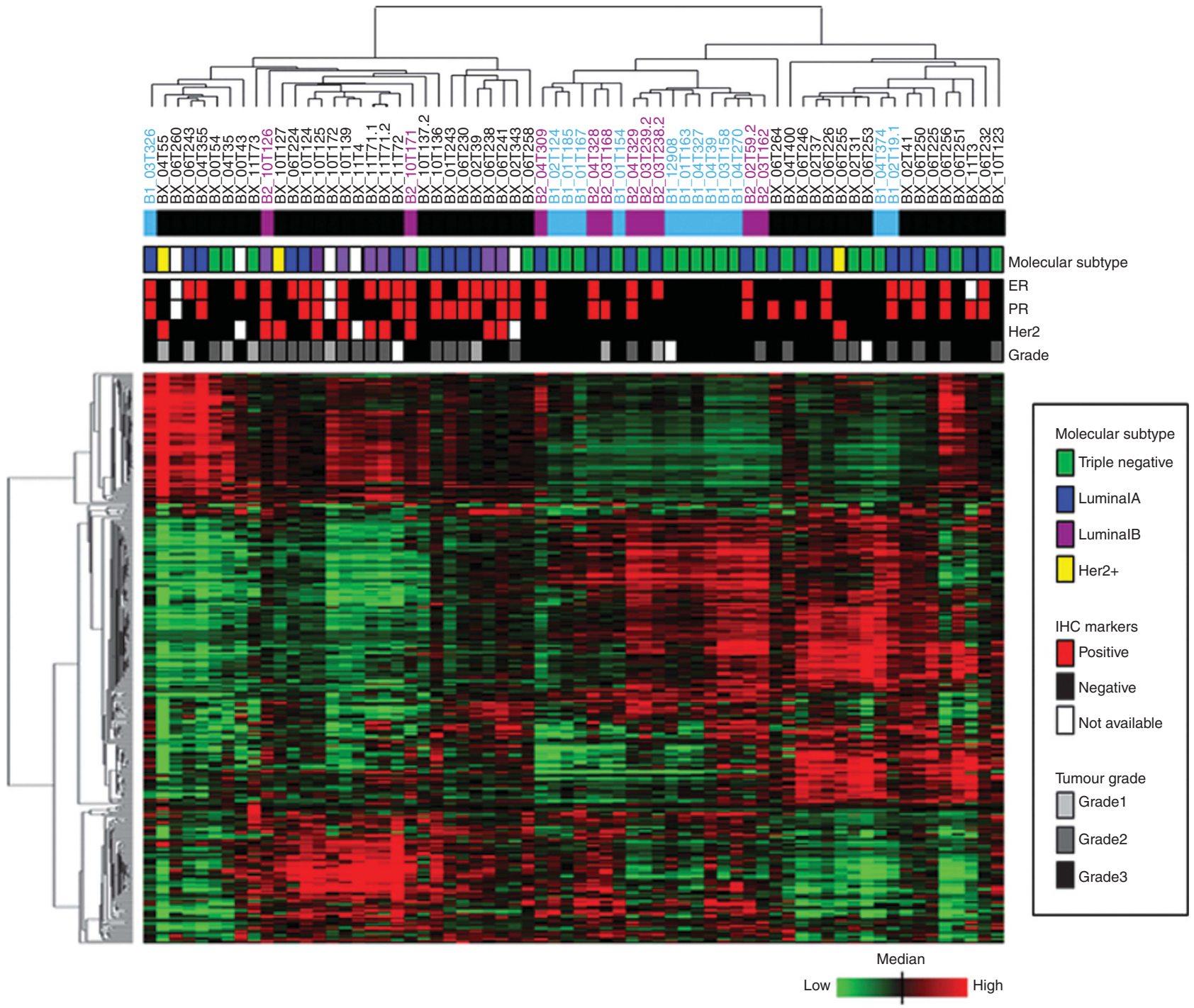

Figure 1. Clustering analysis of hereditary breast tumours. Heatmap showing unsupervised hierarchical clustering (average linkage clustering, Pearson correlation coefficient, median centred) of 80 FFPE breast tissue samples over 444 miRNAs.

73 miRNAs $\left(R^{2}>0.77\right)$. The full list of miRNA genes within each cluster is shown in Supplementary Table S2.

Next, we explored the expression of the 183 signature miRNAs belonging to miRNA Clusters 1,2 and 3, in the other tumoural samples, 23 BRCA1/2-mutated tumours, 10 sporadic breast tumours and 10 normal breast tissue samples (Figure 3). The expression profile of BRCAX-C group was characterised by lower expression of Cluster 1 and Cluster 2 miRNAs and higher expression of Cluster 3 miRNAs compared with normal breast tissue, and highly resembled that of BRCA1/2 tumours. In the BRCAX-B group, we also observed loss of expression of Cluster 2 miRNAs, whereas Cluster 1 or Cluster 3 miRNAs had similar expression to that of normal breast tissue. The BRCAX-A group shows a similar pattern of expression to that of normal breast tissue. The BRCAX-D group lacked any specific miRNA signature and in that respect it resembles the group of sporadic breast tumours.

In order to quantify the similarity between these tumour groups, we have estimated the Pearson correlation coefficient for the miRNA expression profile constituting 183 signature miRNAs in the defined BRCAX subgroups (A, B, C and D) with their expression in BRCA1/2-mutated tumour, sporadic breast tumours and normal breast tissues (Figure 4A). Highest correlation in miRNA expression for BRCAX-A group was observed with normal breast tissue $\left(R^{2}=0.78, \quad P<0.001\right)$. Expression of signature miRNAs in BRCAX-B tumours did not correlate with any of the groups compared. BRCAX-C tumours demonstrated highest correlation in miRNA expression with BRCA1/2-mutated tumours $\left(R^{2}=0.79, P<0.001\right)$, whereas BRCAX-D tumours had highest correlation in expression to sporadic breast carcinomas $\left(R^{2}=0.90\right.$, $P<0.001$ ) (Figure 4B).

Deregulated miRNA families and clusters. The identified miRNA clusters show subtype-specific pattern of expression. Both BRCAX-B and BRCAX-C subgroups are characterised by loss of expression of miRNA Cluster 2 in comparison to normal breast tissue. This miRNA cluster is composed of 48 miRNAs among which are 5 broadly conserved miRNA families, including 7 out of 9 known members of the let-7 family (let-7a, let7b, let7-c, let-7d, let-7f, let-7g, let-7i), all miR-30 family members (miR-30a, miR-30c, miR-30d, miR-30b, miR-30e), all miR-15 family members (miR-15a, miR-16, miR-15b, miR-195), 4 out of 5 miR-8 family members (miR-200b, miR-200c, miR-200a, miR-141) and all miR-29 family members (miR-29a, miR-29b, miR-29c), in addition to miR-125b and miR-143.

Within the miRNA Cluster 1, which was specifically downregulated in BRCAX-C tumours, we observed an enrichment of very large miRNA cluster located at 19q13.41-42 that consisted of 
A
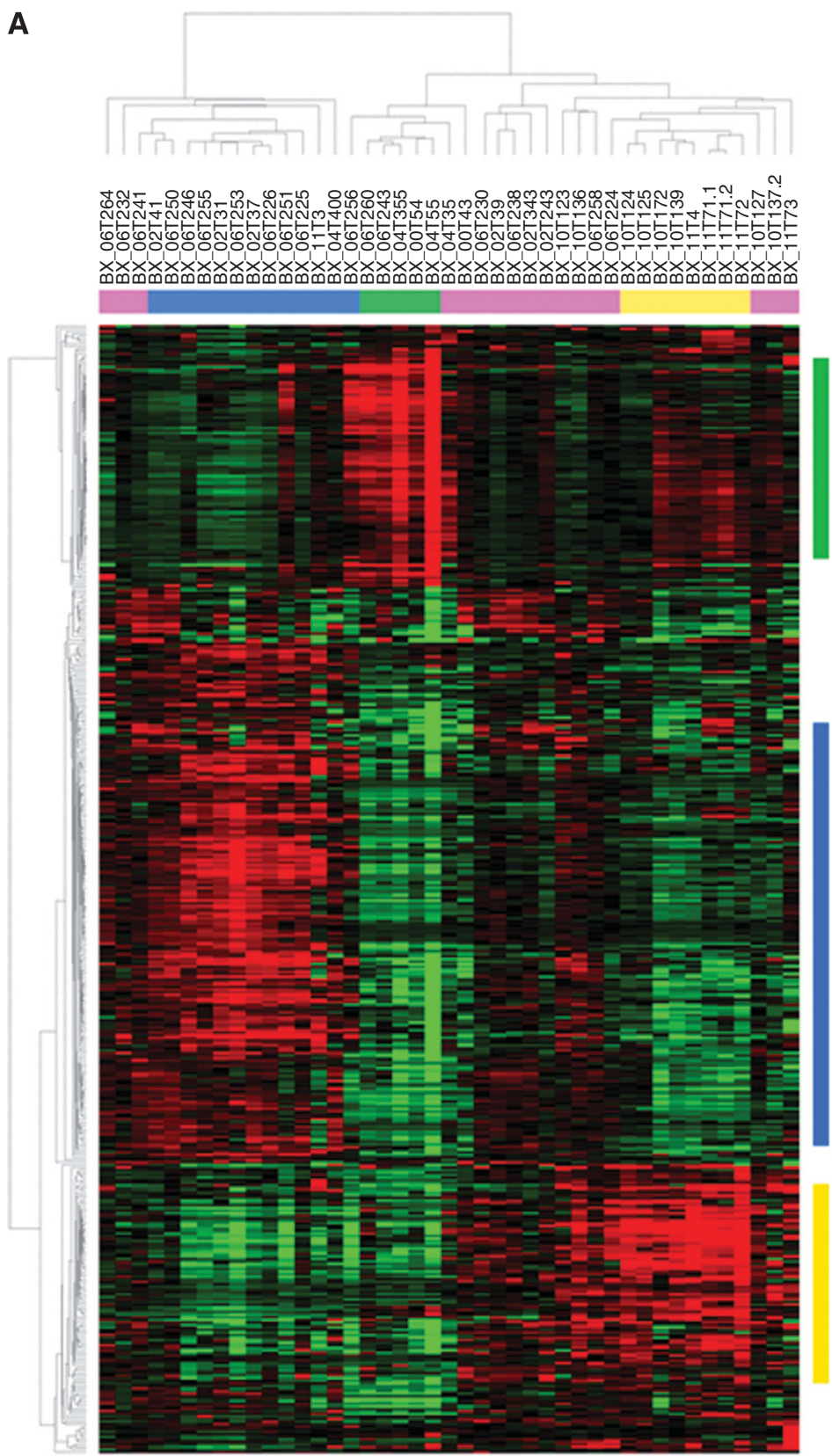

Median

Low High
B

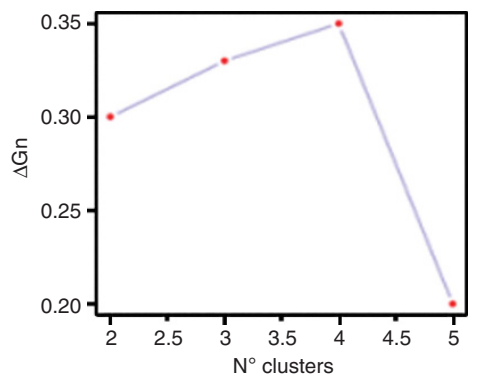

NODE182

$\mathrm{R}^{2}=0.82$

C

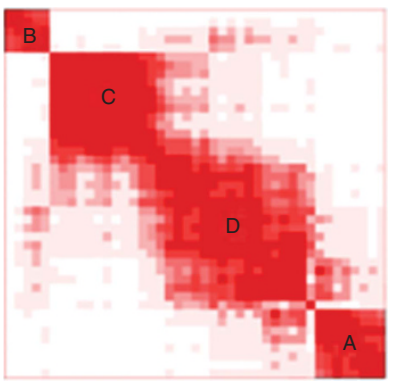

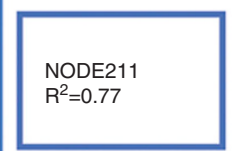

NODE209

$\mathrm{R}^{2}=0.77$

Figure 2. Clustering analysis of BRCAX breast tumours. (A) Unsupervised hierarchical clustering of 43 BRCAX tumours over 444 miRNAs ( $v>0.1)$. (B) Bootstrap analysis of the BRCAX series by Consensus Clustering algorithm (GenePattern, Broad Institute) by reiteration of K-NN Means $(K=1,2,3,4,5)$ clustering with Euclidian distance metrics. Plot shows the change in free energy $(\Delta \mathrm{Gn})$ with each additional subgroup added, indicating that optimal number of clusters within this series is four. (C) Red squares in the consensus matrix represent subgroups of BRCAX tumours in which the samples were more robustly distributed based on their miRNA expression profile. Four subgroups of tumours were identified and denominated as BRCAX-A (yellow), BRCAX-B (green), BRCAX-C (blue) and BRCAX-D (pink).

nine primate-specific miRNAs (miR-99b*, miR-373, miR-517c, miR-519c-3p, miR-519d, miR-520d-3p, miR-520h, miR-522 and miR-526b). Members of the miRNA Cluster 3, overexpressed specifically in the BRCAX-C group, included 6 out of 11 members of the primate-specific miR-506 family (miR-508-5p, miR-509-3-5p, miR-510, miR-513b, miR-509-5p, miR-513a-5p) located at a very large miRNA cluster at chromosome Xq27.3 region, and miR-154 family members (miR-381, miR-323-3p and $\mathrm{miR}-494$ ) and miR-299-3p located at miRNA cluster at $14 \mathrm{q} 32.31$.
In order to quantify the level of miRNA deregulation within each of BRCAX subgroups, we have performed differential expression analysis comparing each subgroup to normal breast tissue. Only 14 miRNAs were differentially expressed between BRCAX-A tumours and normal breast tissue samples, whereas other BRCAX subgroups demonstrated much greater miRNA deregulation, with BRCAX-C having the largest number of deregulated miRNAs (Table 1). In addition, BRCAX-C tumours had 64 miRNAs specifically deregulated in this subgroup, whereas 


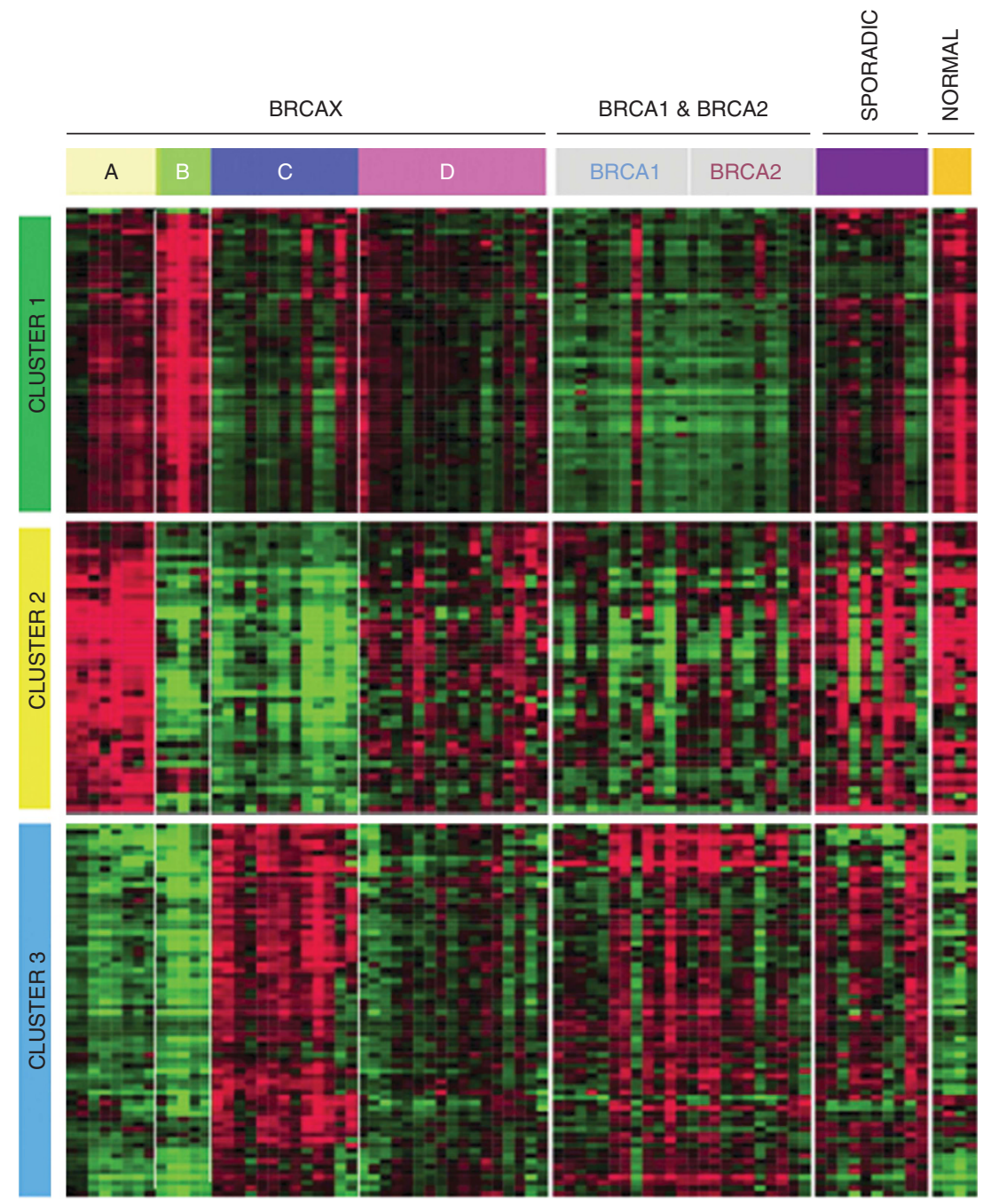

Figure 3. Supervised clustering of 43 BRCAX tumours, 23 BRCA1/2-mutated tumours, 10 sporadic breast tumours and 10 normal breast tissues over 180 miRNAs belonging to signature miRNA Cluster 1 (62 miRNAs), Cluster 2 (48 miRNAs) and Cluster 3 (70 miRNAs). Tumour samples are represented in columns and miRNA gene expression in rows in a red-black-green pseudo-colour scale. Red corresponds to expression higher than media, black equal to median and green lower than median.

only two miRNAs, miR-143 and miR-125b, were commonly deregulated in all four groups showing more than two-fold downregulation in each subgroup. Interestingly, the miR-200 family is upregulated in BRCAX-A tumours and downregulated in the BRCAX-C and BRCAX-B subgroups.

The full list of miRNAs within each Cluster, their genomic location, FDR-corrected $P$-values and fold change in expression comparing to normal breast tissue within each tumour group is represented in Supplementary Table S3.

Prediction analysis of genes and pathways associated with miRNA clusters. To determine the potential biological impact of differential expression of these miRNA clusters between BRCAX subgroups, we sought to identify their target genes and associated pathways. Available target prediction algorithms have high falsepositive rates, which, given the large number of miRNAs per cluster, gave unreasonably high number of potential target genes (several thousands) hindering any pathway-enrichment analysis. Therefore, we have focused our analysis only on confirmed miRNA targets. For each miRNA in a cluster, we have compiled a list of experimentally validated target genes from Tarbase, miRTarBase, miRecords and Ingenuity Systems Knowledge database. We performed gene-set enrichment analysis to highlight the most relevant GOterms associated with a given gene list of mRNA targets within each miRNA cluster, using the DAVID 6.7 bioinformatic tool (Huang da et al, 2009). The top 10 statistically significant GO functional categories enriched in each dataset are represented in Table 2.

Analysis of target genes for miRNA Cluster 2 revealed enrichment in terms related to cell-death regulation, cell-cycle regulation and cell proliferation. This miRNA cluster is commonly downregulated in the BRCAX-B and BRCAX-C groups, suggesting that their mRNA targets are upregulated. Cluster 1 miRNA target genes were significantly associated in addition to regulation of cell proliferation and cell death, to regulation of cell motility and migration. This cluster is specifically lost in BRCAX-C tumours in contrast to BRCAX-B tumours. Target genes for miRNA Cluster 3, specifically upregulated in BRCAX-C tumours, showed most significant association to functional terms related to regulation of metabolism and biosynthesis of macromolecules.

Histopathological characteristics of BRCAX subgroups. Given that here-identified BRCAX subgroups have specific miRNA signatures associated with different cellular functions, we proceeded to examine whether any differences were present between BRCAX subgroups at the histopathological level. In order to test for the homogeneity in the distribution of imunochistochemical markers for ER, PR, HER2, Ki-67, tumour grade and molecular 
A
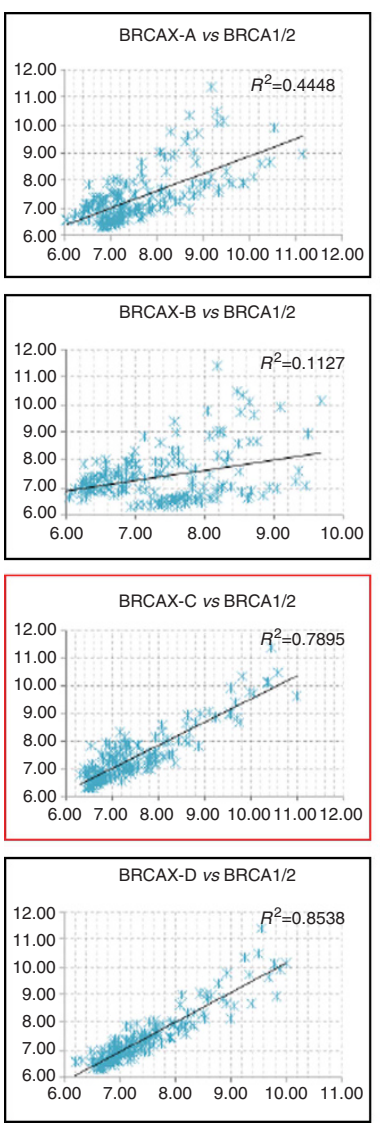
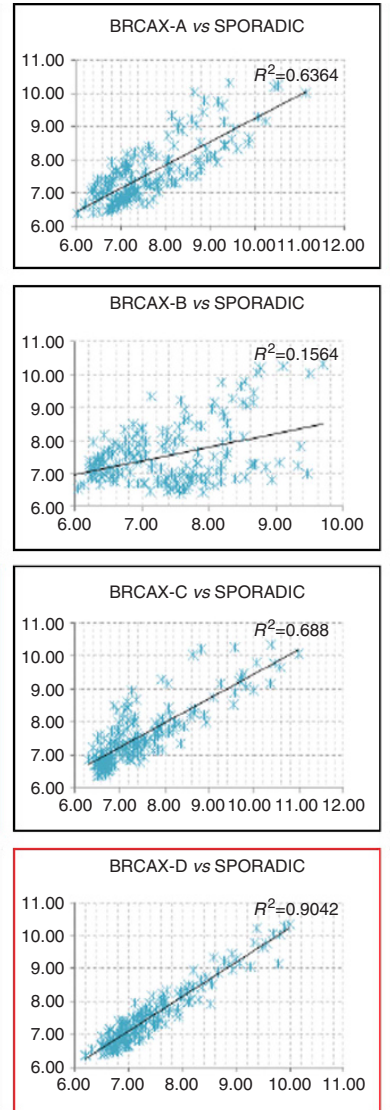

B
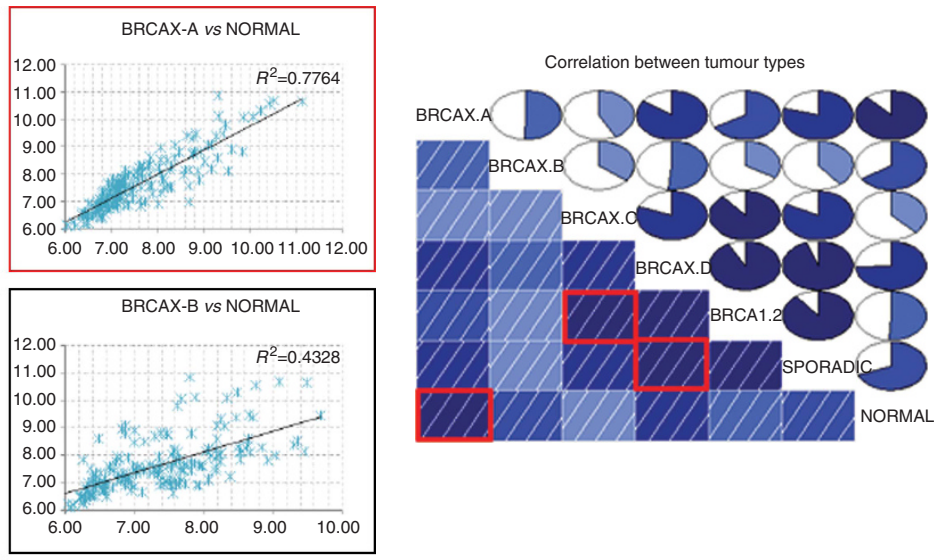
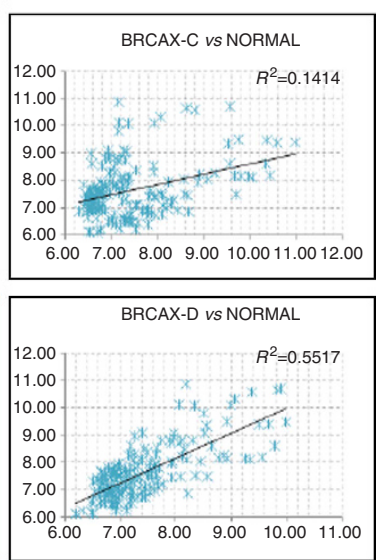

Figure 4. (A) Scatter plot of miRNA expression for 183 miRNAs belonging to the three signature clusters (Cluster 1, Cluster 2 and Cluster 3) between BRCAX subgroups (A, B, C and D), BRCA1 and BRCA2-mutated tumours, sporadic breast tumours and normal breast tissue. A linear regression curve was fitted using least squares method and squared Pearson correlation coefficient $\left(R^{2}\right)$ is represented. Highlighted in red are most highly correlated expression profiles for each of the subgroups. (B) Correlogram representing correlation matrix of expression over 138 signature miRNAs. The colour intensity increases with increased correlation.

Table 1. Summary of differentially expressed miRNAs (FDR adjusted $P$-value $<0.05$ ) by limma $t$-test analysis comparing miRNA expression profiles of BRCAX subgroups to normal breast tissue

\begin{tabular}{|l|c|c|c|}
\hline $\begin{array}{l}\text { Tumour } \\
\text { subtype }\end{array}$ & $\begin{array}{c}\text { Upregulated } \\
\text { miRNAs }\end{array}$ & $\begin{array}{c}\text { Downregulated } \\
\text { miRNAs }\end{array}$ & $\begin{array}{c}\text { Total differentially } \\
\text { expressed miRNAs }\end{array}$ \\
\hline BRCAX-A & 7 & 7 & 14 \\
\hline BRCAX-B & 1 & 37 & 38 \\
\hline BRCAX-C & 67 & 85 & 152 \\
\hline BRCAX-D & 18 & 56 & 74 \\
\hline
\end{tabular}

subtype between the subgroups of BRCAX tumours, we used twotailed Fisher's exact test. No significant differences were found in the distribution of ER or PR markers, whereas there were significant differences in the expression of HER2 and molecular subtype between different BRCAX subgroups (Table 3). BRCAX-A tumours were significantly enriched for HER2-positive tumours $(P=0.034)$ and had significantly higher proportion of Luminal B subtype $(P=0.008)$. Of note, BRCAX-A tumours were clustering along other HER2-positive tumours in the unsupervised analysis (Figure 1). Furthermore, BRCAX-A subgroup significantly comprised lower-grade tumours (only grade 1 and grade 2 tumours) in comparison with other BRCAX subgroups. Although not reaching statistical significance, it is worth noticing that BRCAX-C tumours are consisted exclusively of grade 2 and grade 3
(Table 3) and are associated with lymph node-positive tumours $(P=0.075)$, whereas BRCAX-A tumours tend to be lymph nodenegative $(P=0.088)$.

\section{DISCUSSION}

The underlying biology of BRCA1/2-negative hereditary breast cancer is still largely unknown despite intensive research in past two decades. The notorious heterogeneity of BRCAX tumours has been demonstrated using various technological platforms including gene expression profiling, comparative genomic hybridisation (CGH), immunohistochemistry, $\mathrm{LOH}$ and methylation studies (Honrado et al, 2007). Understanding the biology behind BRCAX tumour heterogeneity could allow for guiding optimal therapeutic and preventive options, and may help stratify BRCAX families for linkage analysis. Here we have examined whether the heterogeneous genetic background of BRCAX tumours could be resolved using miRNA expression profiling.

Unsupervised clustering analysis of BRCAX tumours based on their miRNA expression demonstrated once again the heterogeneous nature of these tumours, with several apparent subgroups. Class discovery algorithm reviled the existence of four different subgroups, characterised by a specific miRNA signature (BRCAX-A, -B, $-\mathrm{C}$ and $-\mathrm{D})$, consisted of three miRNA clusters defined based on their co-expression. The subgroup of BRCAX-A tumours 


\begin{tabular}{|c|c|c|}
\hline Cluster 1 & GO term & FDR \\
\hline 1 & Regulation of programmed cell death & $3.8636 \mathrm{E}-12$ \\
\hline 2 & Regulation of cell death & 4.6296E-12 \\
\hline 3 & Regulation of apoptosis & 6.5259E-11 \\
\hline 4 & Positive regulation of cell motion & 7.1054E-11 \\
\hline 5 & Regulation of cell proliferation & 6.8739E-10 \\
\hline 6 & Regulation of cell motion & $9.2683 \mathrm{E}-10$ \\
\hline 7 & Positive regulation of cell migration & 3.6592E-09 \\
\hline 8 & Positive regulation of locomotion & 1.5643E-08 \\
\hline 9 & Regulation of cell migration & 6.5907E-08 \\
\hline 10 & Regulation of locomotion & 6.7346E-08 \\
\hline Cluster 2 & GO term & FDR \\
\hline 1 & Regulation of cell proliferation & $2.3163 \mathrm{E}-23$ \\
\hline 2 & $\begin{array}{l}\text { Positive regulation of macromolecule metabolic } \\
\text { process }\end{array}$ & $1.2576 \mathrm{E}-18$ \\
\hline 3 & Regulation of programmed cell death & 7.4208E-17 \\
\hline 4 & Regulation of cell death & $9.7426 \mathrm{E}-17$ \\
\hline 5 & Regulation of apoptosis & $3.6393 \mathrm{E}-16$ \\
\hline 6 & Positive regulation of developmental process & 6.7366E-15 \\
\hline 7 & Regulation of phosphate metabolic process & $1.2121 \mathrm{E}-14$ \\
\hline 8 & Regulation of phosphorus metabolic process & $1.2121 \mathrm{E}-14$ \\
\hline 9 & $\begin{array}{l}\text { Positive regulation of macromolecule biosynthetic } \\
\text { process }\end{array}$ & 1.4034E-14 \\
\hline 10 & Organelle lumen & 1.5989E-14 \\
\hline Cluster 3 & GO term & FDR \\
\hline 1 & Regulation of cell cycle & 1.3737E-05 \\
\hline 2 & $\begin{array}{l}\text { Positive regulation of macromolecule biosynthetic } \\
\text { process }\end{array}$ & 0.00039839 \\
\hline 3 & Positive regulation of cellular biosynthetic process & 0.00061206 \\
\hline 4 & Positive regulation of biosynthetic process & 0.00069981 \\
\hline 5 & $\begin{array}{l}\text { Positive regulation of nitrogen compound } \\
\text { metabolic process }\end{array}$ & 0.00393855 \\
\hline 6 & $\begin{array}{l}\text { Positive regulation of macromolecule metabolic } \\
\text { process }\end{array}$ & 0.00474381 \\
\hline 7 & Regulation of protein kinase activity & 0.00578571 \\
\hline 8 & $\begin{array}{l}\text { Transmembrane receptor protein tyrosine kinase } \\
\text { signalling pathway }\end{array}$ & 0.006535 \\
\hline 9 & Regulation of kinase activity & 0.00725011 \\
\hline 10 & Regulation of transferase activity & 0.00950461 \\
\hline
\end{tabular}

showed overall similar levels of miRNA expression to normal breast tissue and thus were denominated as 'normal-like' BRCAX-A tumours hereafter. BRCAX-B tumours on the other hand were differentiated from normal tissue only by the downregulation of Cluster 2 miRNAs related to pathways regulating cell proliferation, cell death and cell cycles. The miRNA expression profile of the BRCAX-C tumour group demonstrated inverse expression levels to that of normal breast tissue and highly resembled that of BRCA1 and BRCA2 tumours, characterised by downregulation of Cluster 1 and Cluster 2 miRNAs related to cell proliferation and migration, overexpression of Cluster 3 miRNAs related to macromolecule biosynthesis and were denominated as 'BRCA1/2-like' BRCAX-C tumours. On the other hand, BRCAX-D tumours did not show any specific miRNA signature and in that respect demonstrated a 'sporadic-like' phenotype.

Comparing to normal breast tissue only two miRNAs, miR-125b and miR-143, were commonly deregulated in all four BRCAX tumour subgroups. Both miR-125b and miR-143 are well described as tumour-suppressor miRNAs in breast cancer (Heinonen et al, 2005; Iorio et al, 2005; Volinia et al, 2006) that are negatively regulating RAS signalling in case of miR-143
(Kent et al, 2012) and HER2 and HER3 in case of miR-125b (Scott et al, 2007). Interestingly, miR-125b is located at chromosome 11q23-24, one of the regions most frequently deleted in breast, ovarian and lung tumours (Negrini et al, 1995).

Micro RNAs belonging to Cluster 1, specifically downregulated in 'BRCA1/2-like' BRCAX-C tumours, were enriched for a large number of primate-specific miRNAs localised at chromosome 19q13.41-42 (Zhang et al, 2008). Interestingly, this region is genetically altered in a variety of tumours featuring deletions, amplifications and translocations (Toledo et al, 2010; Forzano et al, 2012), and the C19MC miRNA cluster has been extensively implicated in cancer and other diseases (Pfister et al, 2009; Rippe et al, 2010; Vaira et al, 2012). Bioinformatic analysis of Cluster 1 miRNA target genes related their function to positive regulation of cell migration and motility, in addition to regulation of cell proliferation and apoptosis. Cluster 2, downregulated in BRCAX-B and 'BRCA1/2-like' BRCAX-C tumours, contained well-known tumour-suppressor miRNAs implicated in breast pathogenesis of both sporadic and hereditary cancer, including all members of let-7 and miR-30 family, that are regulating cell proliferation and differentiation in breast setting (Le Quesne and Caldas, 2010; Tanic et al, 2012). Other tumour-suppressor miRNAs in this cluster included commonly downregulated miR-125b and miR-143. Loss of these tumour-suppressor miRNAs would lead to concomitant increase in proliferation rates and de-differentiation. Interestingly, the miR-8 family members (miR-141/200a/200b/200c) were more than two-fold upregulated in 'normal-like' BRCAX-A tumours, whereas being downregulated in BRCAX-B and 'BRCA1/2-like' BRCAX-C subgroups. This miRNA family acts as suppressor of epithelial to mesenchymal transition (Burk et al, 2008) is implicated in the maintenance of stem cell phenotype and downregulated in the mammary progenitor cells (Shimono et al, 2009). As expected, genes related to miRNA Cluster 2 were associated with pathways regulating cell death, cell proliferation, developmental processes and macromolecule metabolism. Cluster 3 miRNAs were specifically overexpressed in 'BRCA1/2like' BRCAX-C tumours and contained a very large primatespecific miRNA cluster located at chromosome Xq27.3 (Zhang et al, 2008). Noteworthy, this region was linked to testicular germ cell tumours (Rapley et al, 2000) and hereditary prostate cancer (Lange et al, 1999; Peters et al, 2001), and miRNAs in the cluster were implicated in clear cell renal carcinoma (Zhou et al, 2010). Biological functions associated with target genes of Cluster 3 miRNAs were regulation of cell cycle, protein kinase activity and biosynthesis of macromolecules.

It is possible that miRNA deregulation would be a consequence of specific genomic alterations occurring in the tumour. A previous paper by our group performed aCGH analysis in familial breast cancer, although in an independent tumour set, and defined different chromosomal regions mainly associated with the molecular subtypes of breast cancer (Melchor et al, 2008). In this study, BRCAX tumours were mostly Luminal A, showing recurrent gains in $1 \mathrm{q}$ and $16 \mathrm{p}$ and recurrent losses in $11 \mathrm{q}$ or $16 \mathrm{q}$, although tumours with Basal-like phonotype showed higher genomic instability with many altered chromosomal regions (recurrent gains at 1q, 3q, 8q, 17q or recurrent losses at 3p, 4p 4q, 5q, 8p, 10q, $11 \mathrm{q}, 12 \mathrm{q} \mathrm{13q}, 14 \mathrm{q} 15 \mathrm{q}, 16 \mathrm{q}, 22 \mathrm{q})$. Most of these regions have also been identified in other relevant studies (Cancer Genome Atlas, 2012). Significantly, many of the differentially expressed miRNAs in BRCAX subgroups (Supplementary Table 3) are located in gained or lost regions defined by us and others but a direct causality cannot be established. For instance, commonly downregulated hsa-miR-125b or hsa-miR-130 are located in $11 \mathrm{q}$, a region frequently lost in breast cancer. In addition, some miRNAs of our Cluster 3 (hsa-miR-765, hsa-miR-921, hsa-miR-557 or hsa-miR-215) located in 1q, a region frequently gained, were found overexpressed specifically in the BRCAX-C group. 
Table 3. Clinico-pathological data for BRCAX hereditary breast tumours by subtype

\begin{tabular}{|c|c|c|c|c|c|c|c|c|}
\hline & BRCAX-A & BRCAX-B & BRCAX-C & BRCAX-D & & sided & exact $t$ & \\
\hline Total no. & $\begin{array}{l}n=8 \\
n(\%)\end{array}$ & $\begin{array}{l}n=5 \\
n(\%)\end{array}$ & $\begin{array}{c}n=13 \\
n(\%)\end{array}$ & $\begin{array}{c}n=17 \\
n(\%)\end{array}$ & P1 & P2 & P3 & P4 \\
\hline Age at diagnosis & 7 & 5 & 12 & 16 & NS & NS & NS & NS \\
\hline $\begin{array}{l}\text { Mean } \\
\text { Range }\end{array}$ & $\begin{array}{l}44.71 \\
31-54\end{array}$ & $\begin{array}{l}46.60 \\
26-64\end{array}$ & $\begin{array}{l}47.25 \\
33-68\end{array}$ & $\begin{array}{l}49.81 \\
25-95\end{array}$ & & & & \\
\hline $\begin{array}{l}1 \\
2 \\
3\end{array}$ & $\begin{array}{c}1(14.3) \\
6(85.7) \\
0(0)\end{array}$ & $\begin{array}{l}1(20.0) \\
2(40.0) \\
2(40.0)\end{array}$ & $\begin{array}{c}0(0) \\
5(41.7) \\
7(58.3)\end{array}$ & $\begin{array}{l}2(11.8) \\
7(41.2) \\
8(47.1)\end{array}$ & & & & \\
\hline Oestrogen receptor & 7 & 4 & 12 & 17 & 0.095 & 1.000 & 0.170 & 1.000 \\
\hline $\begin{array}{l}\text { Positive } \\
\text { Negative }\end{array}$ & $\begin{array}{l}6 \text { (85.71) } \\
1(14.29)\end{array}$ & $\begin{array}{l}2(50.0) \\
2(50.0)\end{array}$ & $\begin{array}{l}4(33.3) \\
8(66.7)\end{array}$ & $\begin{array}{l}9(52.9) \\
8(47.1)\end{array}$ & & & & \\
\hline HER2 & 7 & 5 & 13 & 15 & $0.034^{*}$ & 1.000 & 0.226 & 1.000 \\
\hline $\begin{array}{l}\text { Positive } \\
\text { Negative }\end{array}$ & $\begin{array}{l}4(57.14) \\
3(42.86)\end{array}$ & $\begin{array}{l}1(20.0) \\
4(80.0)\end{array}$ & $\begin{array}{c}1(7.7) \\
12(92.3)\end{array}$ & $\begin{array}{c}3(20.0) \\
12(80.0)\end{array}$ & & & & \\
\hline Subtype & 6 & 4 & 13 & 15 & $0.008^{*}$ & 0.499 & 0.295 & 0.886 \\
\hline $\begin{array}{l}\text { Luminal A } \\
\text { Luminal B } \\
\text { HER2 } \\
\text { Triple negative }\end{array}$ & $\begin{array}{c}2(33.33) \\
4(66.67) \\
0(0) \\
0(0)\end{array}$ & $\begin{array}{l}2(50.0) \\
0(0) \\
1(25.0) \\
1(25.0)\end{array}$ & $\begin{array}{l}4(30.8) \\
1(7.7) \\
1(7.7) \\
7(53.8)\end{array}$ & $\begin{array}{l}7(46.7) \\
2(13.3) \\
1(6.7) \\
5(33.3)\end{array}$ & & & & \\
\hline Lymph node & 6 & 3 & 12 & 14 & 0.088 & 1.000 & 0.075 & 0.500 \\
\hline $\begin{array}{l}\text { Positive } \\
\text { Negative }\end{array}$ & $\begin{array}{l}1 \text { (16.7) } \\
5(83.3)\end{array}$ & $\begin{array}{l}2(66.7) \\
1(33.3)\end{array}$ & $\begin{array}{l}9(75.0) \\
3(25.0)\end{array}$ & $\begin{array}{l}6(42.9) \\
8(57.1)\end{array}$ & & & & \\
\hline
\end{tabular}

It is known that miRNA expression is highly specific for the tissue of origin and developmental stage (Landgraf et al, 2007; Niwa and Slack, 2007). In effect, miRNA profiling is emerging as a powerful diagnostic tool to characterise features of different tumour types and has been particularly useful in breast cancer as miRNA signatures can unequivocally distinguish normal and malignant breast tissue. Therefore, we can hypothesise that deregulation of specific miRNAs could indicate different pathways of tumour evolution in each of the BRCAX subgroups that may harbour predisposing mutations in specific pathways.

In light of the recent findings by The Cancer Genome Atlas Network that interrogated over 800 sporadic breast carcinomas by five platforms (genomic DNA copy number arrays, DNA methylation, exome sequencing, mRNA arrays, microRNA sequencing and reverse phase protein arrays) and established the existence of four main subgroups of breast cancer, each of which shows significant molecular heterogeneity with specific pattern of somatic mutations, it would be of great importance to examine whether these subtypes could be replicated in hereditary breast tumours as well.

Lack of association of hormone receptor status with a specific tumour subgroup excludes the possibility that miRNA signatures characterising these BRCAX subgroups are associated with endocrine response to oestrogen or progesterone. However, other underlying genetic alterations or external signalling could be reflected in the observed miRNA profiles. 'Normal-like' BRCAX-A tumours were the only subgroup significantly associated with specific histopathological features, specifically to HER2 overexpression. Although HER2 overexpression is associated with poor prognosis, these tumours were of moderate grade $(P=0.03)$ and lymph node negative $(P=0.08)$, both of which are clinical parameters associated with good prognosis. Micro RNA expression profile in 'normal-like' BRCAX-A tumours closely resembles that of normal breast tissue, unlike massive miRNA deregulation observed in other tumour subgroups, implying that in these tumours overactive HER2 signalling is important for the tumourigenesis process. The BRCAX-B subgroup of tumours was not significantly different in terms of histopathological characteristics from the rest of tumours. In fact, these tumours are characterised by the downregulation of tumour-suppressor miRNAs, important for pathogenesis of both hereditary and sporadic tumours (Tanic et al, 2012). On the other hand, 'BRCA1/ 2-like' BRCAX-C tumours in addition to downregulation of Cluster 2 tumour-suppressor miRNAs had subtype-specific aberrantly expressed miRNAs. These tumours comprised only high- and moderate-grade tumours, although not statistically significant, and were enriched for lymph node-positive tumours, both characteristics being related to poor prognosis. Given the high similarity in miRNAs expression profiles between 'BRCA1/2-like' BRCAX-C tumours and BRCA1- and BRCA2-mutated tumours, this subgroup of tumours would represent good candidates for resequencing studies focused on the DNA-damage repair pathway.

It is very likely that the group of BRCAX cases is attributable to multiple genetic defects that may fall into the class of rare moderate-risk genes or, more unlikely, in rare high-risk (BRCA-like) genes. However, given that linkage studies have failed 
to identify new susceptibility genes, it is to assume that even if more highly penetrant genes exist, they will not explain the large percentage of remaining families. The power of linkage analysis would increase dramatically if we were able to select homogenous subgroup of patients who would increase the proportion of this potential susceptibility gene. Differences in tumour aetiology reflected in the miRNA expression profile, could improve patients' stratification for linkage analysis or allow for studies of interaction of low-susceptibility alleles in homogenous set of tumours. The identification of miRNA surrogate phenotypes to define BRCAX tumours could be a starting point in the search of novel susceptibility genes.

\section{ACKNOWLEDGEMENTS}

We thank all members of the Human Genetics Group and the Immunohistochemistry Unit of the Spanish National Cancer Research Centre for all their support. This work was funded by grants from Spanish Ministry of Health PI11/01059, PI08/1120 and PI12/00070, from the Fundación Mutua Madrileña 2011 and from Fundación Sandra Ibarra 2011.

\section{REFERENCES}

Benjamini Y, Drai D, Elmer G, Kafkafi N, Golani I (2001) Controlling the false discovery rate in behavior genetics research. Behav Brain Res 125(1-2): 279-284.

Bignell GR, Warren W, Seal S, Takahashi M, Rapley E, Barfoot R, Green H, Brown C, Biggs PJ, Lakhani SR, Jones C, Hansen J, Blair E, Hofmann B, Siebert R, Turner G, Evans DG, Schrander-Stumpel C, Beemer FA, van Den Ouweland A, Halley D, Delpech B, Cleveland MG, Leigh I, Leisti J, Rasmussen S (2000) Identification of the familial cylindromatosis tumour-suppressor gene. Nat Genet 25(2): 160-165.

Blenkiron C, Goldstein LD, Thorne NP, Spiteri I, Chin SF, Dunning MJ, Barbosa-Morais NL, Teschendorff AE, Green AR, Ellis IO, Tavare S, Caldas C, Miska EA (2007) MicroRNA expression profiling of human breast cancer identifies new markers of tumor subtype. Genome Biol 8(10): R214.

Bradbury AR, Olopade OI (2007) Genetic susceptibility to breast cancer. Rev Endocr Metab Disord 8(3): 255-267.

Burk U, Schubert J, Wellner U, Schmalhofer O, Vincan E, Spaderna S, Brabletz T (2008) A reciprocal repression between ZEB1 and members of the miR-200 family promotes EMT and invasion in cancer cells. EMBO Rep 9(6): 582-589.

Cancer Genome Atlas N (2012) Comprehensive molecular portraits of human breast tumours. Nature 490(7418): 61-70.

Croce CM (2009) Causes and consequences of microRNA dysregulation in cancer. Nat Rev Genet 10(10): 704-714.

Eisen MB, Spellman PT, Brown PO, Botstein D (1998) Cluster analysis and display of genome-wide expression patterns. Proc Natl Acad Sci USA 95(25): 14863-14868.

Fassan M, Baffa R, Palazzo JP, Lloyd J, Crosariol M, Liu CG, Volinia S, Alder H, Rugge M, Croce CM, Rosenberg A (2009) MicroRNA expression profiling of male breast cancer. Breast Cancer Res 11(4): R58.

Fernandez-Ramires R, Gomez G, Munoz-Repeto I, De Cecco L, Llort G, Cazorla A, Blanco I, Gariboldi M, Pierotti MA, Benitez J, Osorio A (2010) Transcriptional characteristics of familial non-BRCA1/BRCA2 breast tumors. Int J Cancer 128(11): 2635-2644.

Forzano F, Napoli F, Uliana V, Malacarne M, Viaggi C, Bloise R, Coviello D, Di Maria E, Olivieri I, Di Iorgi N, Faravelli F (2012) 19q13 microdeletion syndrome: Further refining the critical region. Eur J Med Genet 55(6-7): 429-432.

Hedenfalk I, Ringner M, Ben-Dor A, Yakhini Z, Chen Y, Chebil G, Ach R, Loman N, Olsson H, Meltzer P, Borg A, Trent J (2003) Molecular classification of familial non-BRCA1/BRCA2 breast cancer. Proc Natl Acad Sci USA 100(5): 2532-2537.

Heinonen M, Bono P, Narko K, Chang SH, Lundin J, Joensuu H, Furneaux H, Hla T, Haglund C, Ristimaki A (2005) Cytoplasmic HuR expression is a prognostic factor in invasive ductal breast carcinoma. Cancer Res 65(6): 2157-2161.

Honrado E, Osorio A, Milne RL, Paz MF, Melchor L, Cascon A, Urioste M, Cazorla A, Diez O, Lerma E, Esteller M, Palacios J, Benitez J (2007) Immunohistochemical classification of non-BRCA1/2 tumors identifies different groups that demonstrate the heterogeneity of BRCAX families. Mod Pathol 20(12): 1298-1306.

Honrado E, Osorio A, Palacios J, Benitez J (2006) Pathology and gene expression of hereditary breast tumors associated with BRCA1, BRCA2 and CHEK2 gene mutations. Oncogene 25(43): 5837-5845.

Honrado E, Osorio A, Palacios J, Milne RL, Sanchez L, Diez O, Cazorla A, Syrjakoski K, Huntsman D, Heikkila P, Lerma E, Kallioniemi A, Rivas C, Foulkes WD, Nevanlinna H, Benitez J (2005) Immunohistochemical expression of DNA repair proteins in familial breast cancer differentiate BRCA2-associated tumors. J Clin Oncol 23(30): 7503-7511.

Huang da W, Sherman BT, Lempicki RA (2009) Systematic and integrative analysis of large gene lists using DAVID bioinformatics resources. Nat Protoc 4(1): 44-57.

Inui M, Martello G, Piccolo S (2010) MicroRNA control of signal transduction. Nat Rev Mol Cell Biol 11(4): 252-263.

Iorio MV, Ferracin M, Liu CG, Veronese A, Spizzo R, Sabbioni S, Magri E, Pedriali M, Fabbri M, Campiglio M, Menard S, Palazzo JP, Rosenberg A, Musiani P, Volinia S, Nenci I, Calin GA, Querzoli P, Negrini M, Croce CM (2005) MicroRNA gene expression deregulation in human breast cancer. Cancer Res 65(16): 7065-7070.

Kent OA, Fox-Talbot K, Halushka MK (2012) RREB1 repressed miR-143/145 modulates KRAS signaling through downregulation of multiple targets. Oncogene 32: 2576-2585.

Landgraf P, Rusu M, Sheridan R, Sewer A, Iovino N, Aravin A, Pfeffer S, Rice A, Kamphorst AO, Landthaler M, Lin C, Socci ND, Hermida L, Fulci V, Chiaretti S, Foa R, Schliwka J, Fuchs U, Novosel A, Muller RU, Schermer B, Bissels U, Inman J, Phan Q, Chien M, Weir DB, Choksi R, De Vita G, Frezzetti D, Trompeter HI, Hornung V, Teng G, Hartmann G, Palkovits M, Di Lauro R, Wernet P, Macino G, Rogler CE, Nagle JW, Ju J, Papavasiliou FN, Benzing T, Lichter P, Tam W, Brownstein MJ, Bosio A, Borkhardt A, Russo JJ, Sander C, Zavolan M, Tuschl T (2007) A mammalian microRNA expression atlas based on small RNA library sequencing. Cell 129(7): 1401-1414.

Lange EM, Chen H, Brierley K, Perrone EE, Bock CH, Gillanders E, Ray ME, Cooney KA (1999) Linkage analysis of 153 prostate cancer families over a 30-cM region containing the putative susceptibility locus HPCX. Clin Cancer Res 5(12): 4013-4020.

Le Quesne J, Caldas C (2010) Micro-RNAs and breast cancer. Mol Oncol 4(3): 230-241.

Liao BY, Zhang J (2006) Low rates of expression profile divergence in highly expressed genes and tissue-specific genes during mammalian evolution. Mol Biol Evol 23(6): 1119-1128.

Lowery AJ, Miller N, Devaney A, McNeill RE, Davoren PA, Lemetre C, Benes V, Schmidt S, Blake J, Ball G, Kerin MJ (2009) MicroRNA signatures predict oestrogen receptor, progesterone receptor and HER2/ neu receptor status in breast cancer. Breast Cancer Res 11(3): R27.

Lu J, Getz G, Miska EA, Alvarez-Saavedra E, Lamb J, Peck D, Sweet-Cordero A, Ebert BL, Mak RH, Ferrando AA, Downing JR, Jacks T, Horvitz HR, Golub TR (2005) MicroRNA expression profiles classify human cancers. Nature 435(7043): 834-838.

Lujambio A, Lowe SW (2012) The microcosmos of cancer. Nature 482(7385): 347-355.

Mattie MD, Benz CC, Bowers J, Sensinger K, Wong L, Scott GK, Fedele V, Ginzinger D, Getts R, Haqq C (2006) Optimized high-throughput microRNA expression profiling provides novel biomarker assessment of clinical prostate and breast cancer biopsies. Mol Cancer 5: 24.

Mavaddat N, Antoniou AC, Easton DF, Garcia-Closas M (2010) Genetic susceptibility to breast cancer. Mol Oncol 4(3): 174-191.

Melchor L, Honrado E, Garcia MJ, Alvarez S, Palacios J, Osorio A, Nathanson KL, Benitez J (2008) Distinct genomic aberration patterns are found in familial breast cancer associated with different immunohistochemical subtypes. Oncogene 27(22): 3165-3175.

Negrini M, Rasio D, Hampton GM, Sabbioni S, Rattan S, Carter SL, Rosenberg AL, Schwartz GF, Shiloh Y, Cavenee WK et al. (1995) Definition and refinement of chromosome 11 regions of loss of heterozygosity in breast cancer: identification of a new region at 11q23.3. Cancer Res 55(14): 3003-3007. 
Niwa R, Slack FJ (2007) The evolution of animal microRNA function. Curr Opin Genet Dev 17(2): 145-150.

Osorio A, Barroso A, Martinez B, Cebrian A, San Roman JM, Lobo F, Robledo M, Benitez J (2000) Molecular analysis of the BRCA1 and BRCA2 genes in 32 breast and/or ovarian cancer Spanish families. Br J Cancer 82(7): $1266-1270$

Palacios J, Honrado E, Osorio A, Cazorla A, Sarrio D, Barroso A, Rodriguez S, Cigudosa JC, Diez O, Alonso C, Lerma E, Sanchez L, Rivas C, Benitez J (2003) Immunohistochemical characteristics defined by tissue microarray of hereditary breast cancer not attributable to BRCA1 or BRCA2 mutations: differences from breast carcinomas arising in BRCA1 and BRCA2 mutation carriers. Clin Cancer Res 9(10 Pt 1): 3606-3614.

Palacios J, Robles-Frias MJ, Castilla MA, Lopez-Garcia MA, Benitez J (2008) The molecular pathology of hereditary breast cancer. Pathobiology 75(2) 85-94.

Peters MA, Jarvik GP, Janer M, Chakrabarti L, Kolb S, Goode EL, Gibbs M, DuBois CC, Schuster EF, Hood L, Ostrander EA, Stanford JL (2001) Genetic linkage analysis of prostate cancer families to Xq27-28. Hum Hered 51(1-2): 107-113.

Pfister S, Remke M, Castoldi M, Bai AH, Muckenthaler MU, Kulozik A, von Deimling A, Pscherer A, Lichter P, Korshunov A (2009) Novel genomic amplification targeting the microRNA cluster at $19 \mathrm{q} 13.42$ in a pediatric embryonal tumor with abundant neuropil and true rosettes. Acta Neuropathol 117(4): 457-464.

Poggio S, Aguilar C, Osorio A, Gonzalez-Pedrajo B, Dreyfus G, Camarena L (2000) sigma(54) Promoters control expression of genes encoding the hook and basal body complex in Rhodobacter sphaeroides. J Bacteriol 182(20): 5787-5792.

Rahman N, Stratton MR (1998) The genetics of breast cancer susceptibility. Annu Rev Genet 32: 95-121.

Rapley EA, Crockford GP, Teare D, Biggs P, Seal S, Barfoot R, Edwards S, Hamoudi R, Heimdal K, Fossa SD, Tucker K, Donald J, Collins F, Friedlander M, Hogg D, Goss P, Heidenreich A, Ormiston W, Daly PA, Forman D, Oliver TD, Leahy M, Huddart R, Cooper CS, Bodmer JG, Easton DF, Stratton MR, Bishop DT (2000) Localization to Xq27 of a susceptibility gene for testicular germ-cell tumours. Nat Genet 24(2): 197-200.

Reich M, Liefeld T, Gould J, Lerner J, Tamayo P, Mesirov JP (2006) GenePattern 2.0. Nat Genet 38(5): 500-501.

Rippe V, Dittberner L, Lorenz VN, Drieschner N, Nimzyk R, Sendt W, Junker K, Belge G, Bullerdiek J (2010) The two stem cell microRNA gene clusters C19MC and miR-371-3 are activated by specific chromosomal rearrangements in a subgroup of thyroid adenomas. PLoS One 5(3): e9485.

Rothe F, Ignatiadis M, Chaboteaux C, Haibe-Kains B, Kheddoumi N, Majjaj S, Badran B, Fayyad-Kazan H, Desmedt C, Harris AL, Piccart M, Sotiriou C (2011) Global microRNA expression profiling identifies MiR-210 associated with tumor proliferation, invasion and poor clinical outcome in breast cancer. PLoS One 6(6): e20980.

Scott GK, Goga A, Bhaumik D, Berger CE, Sullivan CS, Benz CC (2007)

Coordinate suppression of ERBB2 and ERBB3 by enforced expression of micro-RNA miR-125a or miR-125b. J Biol Chem 282(2): 1479-1486.

Shimono Y, Zabala M, Cho RW, Lobo N, Dalerba P, Qian D, Diehn M, Liu H, Panula SP, Chiao E, Dirbas FM, Somlo G, Pera RA, Lao K, Clarke MF (2009) Downregulation of miRNA-200c links breast cancer stem cells with normal stem cells. Cell 138(3): 592-603.

Stratton MR, Rahman N (2008) The emerging landscape of breast cancer susceptibility. Nat Genet 40(1): 17-22.

Tanic M, Yanowsky K, Rodriguez-Antona C, Andres R, Marquez-Rodas I, Osorio A, Benitez J, Martinez-Delgado B (2012) Deregulated miRNAs in hereditary breast cancer revealed a role for miR-30c in regulating KRAS oncogene. PLoS One 7(6): e38847.

Tavazoie SF, Alarcon C, Oskarsson T, Padua D, Wang Q, Bos PD, Gerald WL, Massague J (2008) Endogenous human microRNAs that suppress breast cancer metastasis. Nature 451(7175): 147-152.

Toledo RA, Lourenco Jr DM, Toledo SP (2010) Familial isolated pituitary adenoma: evidence for genetic heterogeneity. Front Horm Res 38: 77-86.

Vaira V, Elli F, Forno I, Guarnieri V, Verdelli C, Ferrero S, Scillitani A, Vicentini L, Cetani F, Mantovani G, Spada A, Bosari S, Corbetta S (2012) The microRNA cluster C19MC is deregulated in parathyroid tumours. J Mol Endocrinol 49: 115-124.

Volinia S, Calin GA, Liu CG, Ambs S, Cimmino A, Petrocca F, Visone R, Iorio M, Roldo C, Ferracin M, Prueitt RL, Yanaihara N, Lanza G, Scarpa A, Vecchione A, Negrini M, Harris CC, Croce CM (2006) A microRNA expression signature of human solid tumors defines cancer gene targets. Proc Natl Acad Sci USA 103(7): 2257-2261.

Volinia S, Galasso M, Sana ME, Wise TF, Palatini J, Huebner K, Croce CM (2012) Breast cancer signatures for invasiveness and prognosis defined by deep sequencing of microRNA. Proc Natl Acad Sci USA 109(8): 3024-3029.

Zhang R, Wang YQ, Su B (2008) Molecular evolution of a primate-specific microRNA family. Mol Biol Evol 25(7): 1493-1502.

Zhou L, Chen J, Li Z, Li X, Hu X, Huang Y, Zhao X, Liang C, Wang Y, Sun L, Shi M, Xu X, Shen F, Chen M, Han Z, Peng Z, Zhai Q, Zhang Z, Yang R, Ye J, Guan Z, Yang H, Gui Y, Wang J, Cai Z, Zhang X (2010) Integrated profiling of microRNAs and mRNAs: microRNAs located on Xq27.3 associate with clear cell renal cell carcinoma. PLoS One 5(12): e15224.

This work is published under the standard license to publish agreement. After 12 months the work will become freely available and the license terms will switch to a Creative Commons AttributionNonCommercial-Share Alike 3.0 Unported License.

Supplementary Information accompanies this paper on British Journal of Cancer website (http://www.nature.com/bjc) 